\title{
Towards Stronger EU Governance of Health Threats after the COVID-19 Pandemic
}

\author{
Andrea RENDA*(i) and Rosa CASTRO**(i)
}

\section{INTRODUCTION}

In just a few months, COVID-19 - a disease caused by a novel coronavirus known as SARS-CoV-2 - appeared in China and quickly spread to the rest of the world, including Europe and the USA. With confirmed cases surpassing 1.2 million, reported deaths approaching 70,000 ${ }^{1}$ and dramatic projections for the next months, ${ }^{2}$ many governments are now facing tragic choices, such as imposing harsh containment and quarantine rules, while a few are betting on "herd immunity" by letting the virus spread widely (this latter strategy was initially announced and later abandoned by the $\mathrm{UK},{ }^{3}$ while it is being adopted to a certain extent in The Netherlands ${ }^{4}$ and Sweden ${ }^{5}$ ). Healthcare workers have been constrained to choose which patients to save and which ones to let die, ${ }^{6}$ and professional health societies have been prompted to issue guidance for these hard choices. ${ }^{7}$ In a triumph of path

\footnotetext{
Professor of Digital Innovation, College of Europe, Bruges, Belgium; Senior Research Fellow, Centre for European Policy Studies, Brussels, Belgium; email: andrea.renda@ceps.eu.

** Senior Scientific Policy Officer, Federation of European Academies of Medicine (FEAM), Brussels, Belgium. The opinions expressed in this article are personal and do not necessarily represent the official position of FEAM or any of its member academies.

1 Figure based on the 6 April 2020 situation report, which is published daily by the World Health Organization at $<$ https://www.who.int/emergencies/diseases/novel-coronavirus-2019/situation-reports>.

2 See MD Shear, M Crowley and J Glanz, "Coronavirus May Kill 100,000 to 240,000 in U.S. Despite Actions, Officials Say”, New York Times, 31 March $2020<$ https://www.nytimes.com/2020/03/31/us/politics/coronavirusdeath-toll-united-states.html>.

3 As initially announced by the UK: <https://www.theguardian.com/world/2020/mar/16/new-data-new-policy-whyuks-coronavirus-strategy-has-changed?CMP=Share_iOSApp_Other $>$.

$4<$ https://www.forbes.com/sites/joshuacohen/2020/03/27/caught-between-herd-immunity-and-national-lockdownholland-hit-hard-by-covid-19/\#673b738c3557>.

5 B Pancevski, “Inside Sweden's Radically Different Approach to the Coronavirus”, Wall Street Journal, 30 March $2020<$ https://www.wsj.com/articles/inside-swedens-radically-different-approach-to-the-coronavirus-11585598175>.

6 J Horowitz, "Italy's Health Care System Groans Under Coronavirus - A Warning to the World", New York Times, 12 March 2020 <https://www.nytimes.com/2020/03/12/world/europe/12italy-coronavirus-health-care.html>.

7 See, among others, Swiss Academy of Medical Sciences, "COVID-19 Pandemic: Triage for Intensive-Care Treatment under Resource Scarcity" (2020) 150 Swiss Medical Weekly w20229; G Meyfroidt et al, "Ethical Principles Concerning Proportionality of Critical Care during the 2020 COVID-19 Pandemic in Belgium: Advice by the Belgian Society of Intensive Care Medicine" (2020), Update 26 March $2020<$ https://www.hartcentrumhasselt.
} of the Creative Commons Attribution-NonCommercial-ShareAlike licence (http://creativecommons.org/licenses/by-nc-sa/ $4.0 /$ ), which permits non-commercial re-use, distribution, and reproduction in any medium, provided the same Creative Commons licence is included and the original work is properly cited. The written permission of Cambridge University Press must be obtained for commercial re-use. 
dependency, most European Union (EU) Member States have taken gradual, sparse and inconsistent steps, such as closing intra-EU borders and limiting the free circulation of medical devices and protective equipment. All of a sudden, the EU - a project that took decades to build - is on the verge of collapse; trust between countries is declining, while trust between citizens is surprisingly on the rise. Fear of the unknown is leading citizens around the world to look for the solidarity of their neighbours and gradually lose interest in what happens across the border, in what economists and historians have already started to term "de-globalisation". ${ }^{8}$ Investors witness the most dramatic nosedive in the recent history of stock exchange indexes and market operators start preparing for the worst economic crisis since World War II.

In this article, we argue that the pandemic was predictable, and yet the level of preparedness shown by countries around the world, including most advanced economies, was wildly insufficient. For what concerns the EU, more coordinated action would have been desirable and has also been sought by the European Commission; however, such attempts arrived too late, and were hampered by fragmented governance, as well as by the lack of an EU-wide risk and crisis management framework.

\section{THE COVID-19 OUTBREAK: CHRONICLE OF A FORETOLD PANDEMIC?}

While many have rushed to describe the outbreak as a "black swan" - an unpredictable event with extremely severe consequences such as the 2008 financial crisis, the dot.com bubble or 9/11 - we have argued elsewhere that COVID-19 was not only predictable ex post but it was amply predicted ex ante. ${ }^{10}$

Unlike the typical "black swan" event, there is no evidence that the SARS-CoV-2 virus was human-made. ${ }^{11}$ More importantly, an outbreak of pandemic dimensions was widely predicted beforehand. The threat of such a pandemic was to be expected, yet it was ignored, despite repeated warnings by experts, ${ }^{12}$ the press $^{13}$ and expert groups such as the 2016 Report of the "High-level Panel on the Global Response to Health Crises", which warned about the need to address existing gaps and "enhance global capacity to rapidly detect and respond to health crises"; ${ }^{14}$ as well as the 2019 Global Preparedness Monitoring Board (an independent monitoring and accountability body

be/professioneel/nieuws-professioneel/ethical-principles-concerning-proportionality-of-critical-care-during-the-covid19-pandemic-advice-by-the-belgian-society-of-ic-medicine $>$.

8 See H James, “A Pandemic of Deglobalization”, Project Syndicate, 28 February $2020<$ https://www.projectsyndicate.org/commentary/covid-19-deglobalization-pandemic-by-harold-james-2020-02>

$9<$ https://www.bloomberg.com/news/articles/2020-03-05/sequoia-capital-warns-startups-of-coronavirus-blackswan-event $>$.

10 A Renda and RJ Castro, "Chronicle of a Pandemic Foretold”, CEPS Policy Insights No 2020-05/March 2020.

11 KG Andersen, A Rambaut, WI Lipkin, EC Holmes and RF Garry, "The Proximal Origin of SARS-CoV-2” (2020) Nature Medicine < https://doi.org/10.1038/s41591-020-0820-9>.

12 L Garrett. "The Next Pandemic?" (2005) 84 Foreign Affairs 3, observing that "highly virulent, highly transmissible pandemic influenza that circulates the world repeatedly for more than a year" would end up killing more people than all the known weapons of mass destruction "save, perhaps, a thermonuclear exchange".

13 <https://time.com/4766624/next-global-security>; <https://hbr.org/2017/04/the-world-needs-a-darpa-styleproject-to-prevent-pandemics $>$.

14 Protecting humanity from future health crises. Report of the High-level Panel on the Global Response to Health Crises <https://digitallibrary.un.org/record/822489? ln=en>. 
to ensure preparedness for global health crises, hosted by the World Health Organization (WHO)), which concluded that "the world is not prepared for a fast-moving, virulent respiratory pathogen pandemic". ${ }^{15}$ A simulation exercise in the USA in October 2019 confirmed "major unmet global vulnerabilities and international system challenges posed by pandemics that will require new robust forms of public-private cooperation", ${ }^{16}$ and around the same time, the Global Health Security Index report reiterated this warning. ${ }^{17}$

Very useful lessons could be learned through several epidemics that occurred over the past decades (SARS, H1N1 and Ebola). And indeed, some of the countries that were most exposed to those pandemics, especially in South-East Asia, have shown an enhanced level of preparedness compared to many others. However, the pandemic has clearly exposed the lack of preparedness at global, EU and national levels. These gaps are now threatening many peoples' lives, healthcare systems, the world economy and even the future of the EU.

\section{Global PREPAREDNESS AND RESPONSE TO PANDEMICS}

The WHO has worked extensively on pandemic preparedness, adapting its strategy to the lessons learned from past outbreaks such as HIV, Ebola, H1N1 and SARS. ${ }^{18}$ The global framework for preparedness for global health emergencies is based on the binding WHO International Health Regulations (IHR 2005). However, important gaps have been identified both at the level of WHO governance (eg funding, lack of coordination between headquarters and regional offices and lack of transparency and accountability), ${ }^{19}$ as well as at the level of national implementation of the IHR. ${ }^{20}$ While a Joint External Evaluation framework exists for countries to assess their national capacities within the IHR, only 17 countries in the wider European region (which comprises 53 countries) have submitted their reports, while five others are preparing to do so. For example, to date, no report is available for Italy, France or Spain. ${ }^{21}$

The Ebola crisis had already evidenced gaps in funding, health system capacities and reporting. It also unveiled the unnecessary and uncoordinated use of travel bans, trade restrictions and quarantines. In addition, the WHO Director General was also accused of waiting too long before declaring a Public Health Emergency of International Concern (PHEIC), which only happened around four months after the Ebola outbreak

\footnotetext{
15 Global Preparedness Monitoring Board, “A World at Risk”, Annual report on global preparedness for health emergencies, September 2019 < https://apps.who.int/gpmb/assets/annual_report/GPMB_annualreport_2019.pdf>.

$16<$ http://www.centerforhealthsecurity.org/event201/recommendations.html>.

17 <https://www.ghsindex.org/wp-content/uploads/2019/10/2019-Global-Health-Security-Index.pdf>.

18 World Health Organization. Strengthening health security by implementing international health regulations: report of the review committee on the functioning of the international health regulations (2005) in relation to the pandemic (H1N1) 2009 (2011).

19 LO Gostin, "Global Health Security after Ebola: Four Global Commissions" (2016) 94 The Milbank Quarterly 34.

20 A Talisuna et al, "Joint External Evaluation of the International Health Regulation (2005) Capacities: Current Status and Lessons Learnt in the WHO African Region" (2019) BMJ Global Health < https://gh.bmj.com/content/4/ 6/e001312>.

$21<$ https://extranet.who.int/sph/jee-dashboard\#collapse-202>.
} 
spread internationally. ${ }^{22}$ Importantly, public budget cuts imposed after the financial crisis (2008) were reportedly part of the problem. Other problems that emerged in the case of Ebola included the absence of sufficient incentives for coordinating research and development activities and important gaps in information and data sharing between institutions, in particular for the coordination of non-pharmaceutical interventions (including quarantines, social gathering restrictions or cordon sanitaire). In the case of COVID-19, a worldwide race has emerged to develop new therapies, vaccines and diagnostic tests, although the ultimate availability and affordability of such technologies would still need to be figured out. ${ }^{23}$ However, a limit in worldwide and even panEuropean data sharing has persisted and manifested itself on an even larger scale. ${ }^{24}$

\section{EU MECHANISMS TO DEAL WITH PANDEMICS: HIGH EXPECTATIONS,} LIMITED TOOLS

A peculiarity of COVID-19 is that it is not only affecting countries with structural deficiencies in their healthcare systems, but also countries that normally have wellfunctioning and well-funded healthcare systems, including EU Member States such as France, Italy and Spain. According to the Treaty on the Functioning of the European Union (TFEU), the EU has a shared competence with Member States in public health matters for aspects defined by the Treaty. Article 168 TFEU calls the EU to act on global health issues by fostering cooperation with third countries and competent international organisations; however, it also establishes that the responsibility of organising their health systems remains in the hands of Member States.

The EU Decision on Serious Cross-border Threats to Health ${ }^{25}$ provides the framework for EU action related to crisis preparedness and responses to cross-border health threats, including the Early Warning and Response System (EWRS) and a Health Security Committee (HSC), which coordinates responses to outbreaks and pandemics, both within and outside the EU.

A dedicated agency - the European Centre for Disease Prevention and Control (ECDC) - was set up in an attempt to strengthen Europe's response capability and to provide technical support to Member States. The ECDC is in charge of the surveillance, detection and risk assessment of threats, epidemiological surveillance and the operation of the EWRS. Consensus on the need for an agency emerged after the SARS outbreak in 2003, and the ECDC became operational already in 2005. Its work was found to be relevant and meaningful in a recent external evaluation, which particularly praised the relevance of the Centre's activities during the Zika and Ebola outbreaks. ${ }^{26}$ However, the same document also reported weaknesses "in the Centre's

\footnotetext{
22 ibid.

23 DP Mancini, "Big Drugmakers under Pressure to Share Patents against Coronavirus", Financial Times, 30 March $2020<$ https://www.ft.com/content/b69afd98-a8af-40d9-b520-4231d9cac68f >.

24 A Flahault, "COVID-19 Cacophony: Is There Any Orchestra Conductor?” (2020) 395 The Lancet 1037.

25 Decision 1082/2013/EU on serious cross-border threats to health [2013] OJ L 293/1, repealing Decision 2119/98/ EC.

$26<$ https://www.ecdc.europa.eu/sites/default/files/documents/third-independent-external-evaluation-of-ECDCreport.pdf $>$.
} 
capacity to adapt to changes in the Member States, particularly reduced national public health spending"; and that the Centre has not been able to adequately cover its staff costs and hire additional staff. Most worrying is the reported lack of adequate cooperation by Member States, in particular in the Epidemic Intelligence Information System (EPIS) and the European Surveillance System (TESSy), a situation now also aggravated by the effects of Brexit. ${ }^{27}$

In spite of having a legally binding instrument (the EU Decision on Serious Crossborder Threats to Health) and a dedicated agency (the ECDC), the EU governance framework remains a work in progress. This is critical for cross-border health threats, the quintessential case calling for harmonisation and coordinated action superseding national borders. ${ }^{28}$ Significant gaps remain on the implementation of the EU Decision on Serious Cross-border Threats to Health, ${ }^{29}$ and the EU framework remains highly limited by the need to respect the competences of EU Member States. ${ }^{30}$ The main coordinating agency - the ECDC - is also understaffed and under-budgeted. Moreover, several aspects will require enhanced attention if the EU wants to improve its preparedness and responsiveness in light of future pandemics.

First, early warning and prevention strategies need to be better integrated with responses. Especially for zoonoses (diseases spreading from animals to humans), collaboration between the animal health and human health sectors is critical. Because many pandemics, including the one caused by SARS-CoV-2, are zoonoses, prevention strategies need to emphasise cross-sectorial collaborations under an integrated One Health approach. ${ }^{31}$ While the current EU approach coordinated by the ECDC is inspired by such an integrated One Health approach, lack of resources and limited information exchange hamper early warnings of diseases at the intersection of animal and human health.

Second, limiting EU competences on public health is highly inefficient during a pandemic response. ${ }^{32}$ During the current outbreak, the ECDC has issued recommendations, including on the criteria for discharging COVID-19 patients, social distancing ${ }^{33}$ and contact tracing. ${ }^{34}$ The European Commission also published recommendations for testing strategies. ${ }^{35}$ However, these recommendations are not

\footnotetext{
27 M Flear, A de Ruijter and M McKee, "Coronavirus Shows How UK Must Act Quickly before Being Shut Out of Europe's Health Protection Systems" (2020) 368 BMJ m400.

28 See R Martin and A Conseil, "Public Health Policy and Law for Pandemic Influenza: A Case for European Harmonization?" (2012) 37 Journal of Health Politics, Policy and Law 1091, reviewing arguments in favour of and against harmonisation at the EU level.

29 European Court of Auditors special report no 28, Dealing with Serious Cross-Border Threats to Health in the EU: Important Steps Taken but More needs to be Done (Luxembourg, Publications Office of the European Union 2016).

30 M Anderson, M McKee and E Mossialos, "Covid-19 Exposes Weaknesses in European Response to Outbreaks" (2020) 368 BMJ m1075.

31 ECDC, "Towards One Health Preparedness", Technical Report, Expert consultation 11-12 December 2017, highlighting that "One Health implementation was made more difficult by poor communication of early warning signals and surveillance results".

32 ibid.

$33<$ https://www.ecdc.europa.eu/en/publications-data/considerations-relating-social-distancing-measures-responsecovid-19-second $>$.

$34<$ https://www.ecdc.europa.eu/sites/default/files/documents/Public-health-management-persons-contact-novelcoronavirus-cases-2020-03-31.pdf $>$.

$35<$ https://ec.europa.eu/info/sites/info/files/covid19_-_eu_recommendations_on_testing_strategies_v2.pdf > .
} 
binding on EU Member States, and national authorities are currently deciding who to test, whether or not to trace contacts and how often and what types of social distancing measures to adopt. While clearly the adoption of severe measures such as quarantines, school closures and suspension of economic activities often needs to be adapted at national or even regional and local levels, there is also a need for coordinating measures to contain or mitigate the spread of communicable diseases. Both the intended and unintended effects of such measures in any one Member State may have important consequences in others (especially at the border). For instance, early announcements of lockdowns in some cities or countries have prompted a large number of people to flee from severely affected areas, possibly aggravating an already difficult situation. ${ }^{36}$ Closing some activities in one Member State while leaving them open in others also had similar effects. ${ }^{37}$

Third, data sharing is key to understanding the evolution of an outbreak and adapting measures as needed. While the ECDC has competences to collect and share data, one important limitation that emerged during the COVID-19 outbreak is the lack of consistency across data. While EU Member States are sharing data, in many circumstances the level of quality and detail varies significantly. For example, not all countries are sharing data on the number of cases by age and sex. And key information such as the criteria adopted for testing, which have a direct effect on the number of confirmed cases and deaths reported, was not fully shared, which also fostered a lack of trust between Member States. ${ }^{38}$ All of these factors have so far limited the ability of EU institutions to learn in real time from data at the EU level, thereby limiting the EU's ability to respond to the pandemic. ${ }^{39}$

\section{From EU governance to national Responses AND HEALTHCARE INVESTMENTS}

Global rules (the WHO IHR of 2005) and EU coordination (the EU Decision on crossborder threats to health and the ECDC) are two elements in setting up a coordinated response plan. An effective approach to prepare and respond to pandemics also needs to rely on strong national institutions. In 2017, a study found many gaps in Member States' legislation, and a staggering lack of available and transparent information about national frameworks, in spite of clear information-sharing obligations set up at EU and global levels. ${ }^{40}$

Against this backdrop, EU Member States have been reluctant to invest in measures to tackle low-risk, high-consequence occurrences. In a world dominated by the quest for economic efficiency, with financial markets ready to award a premium to governments

\footnotetext{
$36<$ https://www.theguardian.com/world/2020/mar/08/leaked-coronavirus-plan-to-quarantine-16m-sparks-chaosin-italy $>$.

37 <https://www.vrt.be/vrtnws/en/2020/03/15/crowds-of-belgian-shoppers-in-dutch-border-towns>.

38 <https://www.nytimes.com/2020/03/20/world/europe/coronavirus-testing-world-countries-cities-states.html>.

39 P Dąbrowska-Kłosińska, "Electronic Systems of Information Exchange as a Key Tool in EU Health Crisis and Disaster Management" (2019) 10 European Journal of Risk Regulation 652.

40 EM Speakman, S Burris and R Coker, "Pandemic Legislation in the European Union: Fit for Purpose? The Need for a Systematic Comparison of National Laws" (2017) 121 Health Policy 1021.
} 
reducing public spending and thereby taxes, there is little place for resilience-orientated policy. The resulting paradox is that those events that scare citizens the most are tackled by many politicians with a macabre taste for risk.

In Europe, the financial crisis led many Member States to impose drastic spending cuts on healthcare in almost every country. Evidence of cutbacks and "an overall declining share of health expenditure going to public health" in the post-financial crisis period has been recently reported. ${ }^{41}$ For instance, the Organisation for Economic Co-operation and Development (OECD) reported that following the economic crisis, health investments per capita in Italy decreased until 2013 and only started to increase very slowly after then. ${ }^{42}$ To capture the capacity of EU healthcare systems to respond to a crisis, the EU Commission and the OECD have developed a series of indicators reflecting on the long-term stability of resources and efficient and strong governance responses, including to plan and forecast healthcare infrastructure and workforce. ${ }^{43}$ Given the rigidity of most public spending on healthcare, cuts inevitably end up affecting research, as well as overall preparedness strategies; as a result, ordinary administration is somehow (barely) guaranteed, but low-probability, highconsequence events such as COVID-19 are often disregarded by public authorities. Lombardy (a crown jewel of Italy when it comes to healthcare) almost collapsed due to the lack of intensive care beds, leaving many patients unattended and many deaths occurring at home rather than in hospitals.

Summing up, both the global ${ }^{44}$ and $E U^{45}$ governance of pandemics appear too fragmented and insufficiently coordinated. Most countries are wildly unprepared, and the existing coordination mechanisms appear too weak to effectively prevent collective action problems, as well as fragmented and sparse reactions, to proliferate. In Europe, the ECDC is likewise insufficiently endowed to effectively coordinate Member States in providing a meaningful response. As in many global governance settings, the current situation can easily lead to collective action problems, as well as strategic behaviour.

\section{Towards a STRENGTHEned EU AFTER THE PANDEMIC}

Once the current emergency is over, and perhaps even before then, EU institutions will have to work in the direction of strengthening EU governance in various ways.

First, there is a need to strengthen the resilience and sustainability of healthcare systems. Health has been found to be a key concern for European citizens and an area for which the EU has been asked to expand its competences and powers. ${ }^{46}$ Apart

41 B Rechel, "Funding for Public Health in Europe in Decline?" (2019) 123 Health Policy 21.

42 OECD and the European Observatory on Health Systems, State of Health in the EU, Italy: Country Health Profile (2019) < https://www.oecd-ilibrary.org/social-issues-migration-health/italy-country-health-profile-2019_cef1e5cben $>$.

43 European Commission, State of Health in the EU, Companion Report (2019) <https://ec.europa.eu/health/sites/ health/files/state/docs/2019_companion_en.pdf>.

44 LO Gostin, MC DeBartolo and EA Friedman, "The International Health Regulations 10 Years On: The Governing Framework for Global Health Security” (2015) 386 The Lancet 2222.

45 Anderson et al, supra, note 30.

46 See Standard Eurobarometer 89 (2018) Spring 2018, Public Opinion in the European Union; Standard Eurobarometer 91 (2019) Spring 2019 Public Opinion in the European Union. 
from generating important returns for society as a whole, ${ }^{47}$ investment in healthcare should be fostered as a way to increase both the resilience and the sustainability of Member States' economies by enabling a transition towards measures that protect, prepare and transform the economy and society. ${ }^{48}$ Resilience also entails cross-border effects and goes beyond pandemic preparedness, both within and outside the health domain. For example, the area of antimicrobial resistance has already been singled out by the United Nations (UN), the WHO, the EU and some national institutions as representing a massive global health and security risk. Reducing vulnerability and increasing resilience are also essential in response to other threats, such as climate change and the protection of biodiversity. However, emphasis on resilience has been frustrated by a generalised quest for cost cutting and short-term economic efficiency in economic policy, which led to the elimination of all redundancy and excess capacity in critical infrastructures, including healthcare. Increasing resilience will not be possible if worldwide, international institutions continue to emphasise unconditional fiscal discipline and financial markets continue to be tied to quarterly reports on public spending. This, too, will have to change.

The same applies to the European Semester: re-orientating it towards sustainable development, as the von der Leyen Commission seems willing to do, would require providing more visibility to existing health, social inclusion and sustainability indicators as well as adding new indicators and monitoring tools, including a careful planning of preparedness for health and other risks (see below). So far, despite the emphasis on a "Triple A" for social policy in the Juncker Commission, the Stability and Growth Pact has largely prioritised fiscal discipline over resilience-orientated investment. The European Semester also potentially supports investment in health: ${ }^{49}$ however, so far it has clearly prioritised fiscal discipline over access to healthcare and promotion of health, putting further pressure on already strained healthcare systems. ${ }^{50}$

Second, beyond resilience, more centralisation in healthcare governance is needed, especially to address health emergencies. The recent evaluation of the EPIS within the ECDC has highlighted important flaws, mostly on the side of Member States. ${ }^{51}$ The voluntary nature of this multi-level cooperation resembles closely the lack of full coordination experienced in a neighbouring field, cybersecurity. ${ }^{52}$ Moreover, the shortage of medical devices and medicines, an already existing problem in the EU,

\footnotetext{
47 R Masters, E Anwar, B Collins, R Cookson and S Capewell, "Return on Investment of Public Health Interventions: A Systematic Review" (2016) BMJ Journal of Epidemiology and Community Health <https://jech.bmj.com/content/71/ 8/827>. See also European Commission, supra, note 43.

48 ARR Manca, P Benczur and E Giovannini, "Building a Scientific Narrative towards a More Resilient EU Society, Part 1: A Conceptual Framework” (2017) EUR 28548 EN <https://publications.jrc.ec.europa.eu/repository/bitstream/ JRC106265/jrc106265_100417_resilience_scienceforpolicyreport.pdf > .

49 N Azzopardi-Muscat, T Clemens, D Stoner and H Brand, "EU Country Specific Recommendations for Health Systems in the European Semester Process: Trends, Discourse and Predictors" (2015) 119 Health Policy 375.

50 EuroHealthNet, "The European Semester 2018 from a Health Equity Perspective”, November $2018<$ https:// eurohealthnet.eu/publication/european-semester-2018-health-equity-perspective $>$.

$51<$ https://www.ecdc.europa.eu/sites/default/files/documents/third-independent-external-evaluation-of-ECDCreport.pdf $>$.

52 L Pupillo, MK Griffith, S Blockmans and A Renda, "Strengthening the EU's Cyber Defence Capabilities", 26 November $2018<$ https://www.ceps.eu/ceps-publications/strengthening-eus-cyber-defence-capabilities >
} 
became more apparent and critical in the current emergency: ${ }^{53}$ problems in the supply of ventilators, protective masks and medicines have shown existing gaps and unveiled opportunities for Europe to act more effectively. A strategic stockpile of medical devices (rescEU) ${ }^{54}$ has now been set up to address the emergency: this, however, occurred only after Member States attempted to implement export bans for critical medical equipment, ignoring any form of solidarity. A stronger role of the EU would have been advisable also with respect to the plethora of policy measures adopted at all levels of government to contain and delay the spread of the virus. Social distancing, travel bans and other similar measures are thought to be ineffective or even dangerous unless enacted in a concerted and coordinated way. The EU has now issued ad hoc recommendations on testing strategies ${ }^{55}$ and community measures, ${ }^{56}$ but this took far too long, putting individuals and healthcare systems unnecessarily at risk.

Third, Europe should ramp up its preparedness for a wider range of large-scale risks, beyond pandemics, and even beyond healthcare. It is important to avoid the repetition of a "panic-neglect-panic" cycle in the face of crisis. On the one hand, Europe must avoid adopting a "disease-by-disease" strategy: as suggested by a UN High-level Panel ${ }^{57}$ that reviewed in 2016 the experience with the Ebola outbreak, governments should avoid the temptation to emphasise "vertical" programmes focusing on specific diseases or toonarrow policy considerations (eg pandemic preparedness) and prioritise comprehensive, whole-of-government programmes aimed at strengthening all aspects of their national health systems. On the other hand, Europe must also avoid a "threat-by-threat" siloed strategy: even if COVID-19 was not human-made, the extent of the disruption it is creating will certainly entice bioterrorists, and it is clear that the rising role of digital technology in supplementing economic activities could make a combined attack (biological and digital) lethal for the world economy. The mounting awareness that most cyberattacks are hybrid (military and civilian) should spread towards analysing the likelihood of multi-vector attacks. Against this background, even if it has already engaged in extensive risk mapping, ${ }^{58}$ Europe does not have a dynamic, agile centre for the prevention of catastrophic risks. The use of high-performance computers, large datasets and advanced risk analysis techniques can support resilience in Europe without requiring massive investment in new facilities and infrastructure for each sector. Such a centre for the prevention of catastrophic risks could coordinate with existing non-executive agencies in specific sectors (eg the European Network and Information Security Agency (ENISA), the ECDC, the European Security and Markets Authority (ESMA) and the European Banking Authority (EBA)) to alert policy-makers on outstanding threats and evolving risks, including multi-vector ones.

\footnotetext{
$53<$ https://www.reuters.com/article/us-health-coronavirus-eu/europe-could-face-more-drug-shortages-as-corona virus-squeezes-supplies-idUSKBN20S1R2>.

$54<$ https://ec.europa.eu/commission/presscorner/detail/en/ip_20_476>.

$55<$ https://ec.europa.eu/info/sites/info/files/covid19_-_eu_recommendations_on_testing_strategies_v2.pdf > .

$56<\mathrm{https} / / /$ ec.europa.eu/info/sites/info/files/covid19_-_eu_recommendations_for_community_measures.pdf $>$.

57 Protecting humanity from future health crises Report of the High-level Panel on the Global Response to Health Crises <https://digitallibrary.un.org/record/822489? ln=en >.

58 European Commission, "Overview of Natural and Man-Made Disaster Risks the European Union May Face", Commission Staff Working Document <https://ec.europa.eu/echo/sites/echo-site/files/swd_2017_176_overview_ of_risks_2.pdf $>$.
} 
With such a support network, the European Commission could create an executive structure that would coordinate emergency responses by identifying the most effective sequence of measures and enable possible redistribution of materials and resources across Member States to ensure the resilience of the whole Union.

Finally, there are many ways to pursue enhanced resilience and responsiveness, but not all of them are compatible with sustainability and democratic values. The challenge is to find an adequate policy mix that safeguards individual rights and liberties, protects the economy and at the same time strengthens government preparedness for cases of epidemics and pandemics. Building healthcare facilities at the national level based on the (current) needs during a pandemic outbreak makes little sense from a policy perspective; increasing capacity should rather be part of a more comprehensive preparedness strategy that includes the ability to react quickly and increase the number of beds, ventilators or other healthcare facilities in times of emergency. Overstocking medicines at the national level is less efficient than doing so at the panEuropean level. Using technology to track the movement of citizens, as is done in China, is incompatible with individual liberties and fundamental rights and can give rise to widespread social discrimination over time. ${ }^{59}$ In the current emergency, the EU has a chance to show that risk management and governance is possible without sacrificing individual fundamental rights and jeopardising solidarity and the bloc's commitment to sustainable development. The President of the European Commission, Ursula von der Leyen, is facing an uphill battle as Member States repeatedly fail to resist the temptation of closing their borders and refusing to cooperate with their neighbours. The COVID-19 emergency is thus becoming an existential challenge for the "geopolitical Commission", and for the EU project as a whole. A cutting-edge approach to risk detection, analysis and management coupled with far-reaching economic stimuli, the responsible use of technology and the commitment to openly sharing research solutions can preserve the role of the EU as a guiding light in these troubled times.

This is, of course, a non-exhaustive list of possible measures that would contribute to better governance and preparedness in the years to come. They are measures to be adopted in quieter times: as John F. Kennedy once famously said, the time to fix the roof is when the sun is shining. It is essential that, once COVID-19 gradually disappears, the lessons learned from these months of lockdown become the foundations of a new approach to risk governance at EU and global levels. The Global Preparedness Monitoring Board raised this same issue very clearly in its latest annual report: "for too long, we have allowed a cycle of panic and neglect when it comes to pandemics: we ramp up efforts when there is a serious threat, then quickly forget about them when the threat subsides". 60 This time will hopefully be different: remembering what went wrong in times of crisis is essential to avoid repeating the same mistakes in the future.

\footnotetext{
59 A Renda, "Will Privacy Be One of the Victims of COVID-19", CEPS in Brief, 23 March $2020<$ https://www.ceps. eu/will-privacy-be-one-of-the-victims-of-covid-19>.

60 Global Preparedness Monitoring Board, supra, note 15.
} 